$15^{\text {th }}$ International Conference on

AEROSPACE SCIENCES \& AVIATION TECHNOLOGY,

ASAT - 15 - May 28 - 30, 2013, Email: asat@mtc.edu.eg,

Military Technical College, Kobry Elkobbah, Cairo, Egypt,

Tel: +(202) 24025292-24036138, Fax: +(202) 22621908

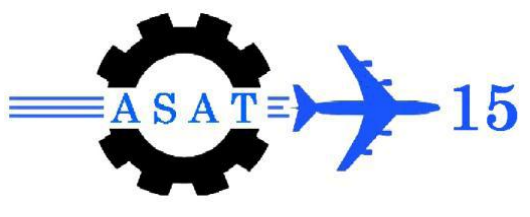

\title{
Decision Maker Support for Site Selection
}

\author{
\{A. R. Mohamady $^{*}$, O. M. Moussa ${ }^{\dagger}$, H. M. El-Hanafy ${ }^{\ddagger}$, H. E. El Hefnawy $\}^{\S}$
}

\begin{abstract}
Military history is full of incidents wherein a smaller army having a good knowledge of the terrain has defeated a much larger well-equipped and organized army. Nearly, all military activities depend on terrain relief and need careful planning and reconnaissance to ensure success. However, planning of military operations is a complex process and is guided by the experience and capability of the commander and his staff who provide him with the necessary and accurate information. The objective of this research is to provide real time access to the intelligence and geographic information produced by the other mission areas in a highly visual setting. Decision Maker Support (DMS) tool can be effectively used to make accurate decision for site selection.

This decision making process can be made intelligent by developing GIS decision maker support system. In this paper, a spatial modeler has been used to produce a number of thematic maps useful for various military operations. The approach developed is capable of taking inputs in the form of data layers that may be generated from satellite images, aerial photographs, topographical maps or other ancillary data. Some common military operations such as selection of sites for small military camps, helipads, identification of tactically important roads and vehicle mobility movement are considered. The development of such spatial modeler decision maker shall tremendously assist the military commander to provide efficient and real-time information in an organized way for any military task.
\end{abstract}

Keywords: site selection, GIS, Decision Maker Support, ERDAS IMAGINE.

\section{Introduction}

In order to carry out careful planning of site selection, especially for military safe requirements, it is required to study ground relief. Some of these requirements are: camouflage, careful vehicles mobility and safe maneuvering, site protection from flash flood and route selection. The problem that faces planners and commanders is how to combine all or most of these requirements in order to select the best site.

The accurate processing of intelligence and geographic data can be used to support military decisions. While imagery intelligence and text reports are primary sources of data for many users, this information is incomplete unless presented in terms of geospatial relationships [1]. The location, context, and activity of a target are key factors that influence these relationships, as well as terrain and weather considerations.

The concept behind geographic imaging is to bring all of these sources together in an unified environment through the use of precise coordinate locations in three dimensions [2].

\footnotetext{
*eng_a_ramzy510@yahoo.com

† eramo87@yahoo.com

*dr_hossam_mohamed@yahoo.com

$\S$ Egyptian Armed Forces, Egypt.
} 
Using a number of feature extraction capabilities within ERDAS IMAGINE, analysts build different thematic layers that represent various geospatial informations covering the study area. These thematic layers can then be synthesized into other products using the spatial modeling ability of ERDAS IMAGINE. For example, in order to understand the positioning of best site, the thematic layers of slope, soil, highways, corridors, and drainage pattern could be synthesized into a map product showing the probability of where a small military camp might be located [3].

Thematic Raster Layers are produced from imagery, reports from analysts, and geographic data. These layers describe the characteristics of the land cover in a particular geographic area, thematic raster layer generally contains pixels that have been classified, or put into distinct categories. Each data file value is a class value, which is simply a number for a particular category. A thematic raster layer is stored in an image file. Only one data file value is stored for each pixel. Since these class values are not necessarily related, the gradations that are possible in true color mode are not usually useful in pseudo color. The class system gives the thematic layer a discrete look, in which each class can have its own color [3].

This paper presents an interface application called Decision Maker Support (DMS) which is used to achieve the objective mentioned above

\section{Study Area}

The study area is located near the Eastern border of Sinai Peninsula, closed to the Gulf of Aqaba. Ground surface is categorized as an undulated and/or rugged topography. It is surrounded by many corridors, one N-S highway and one paved road as shown in (figure 1).

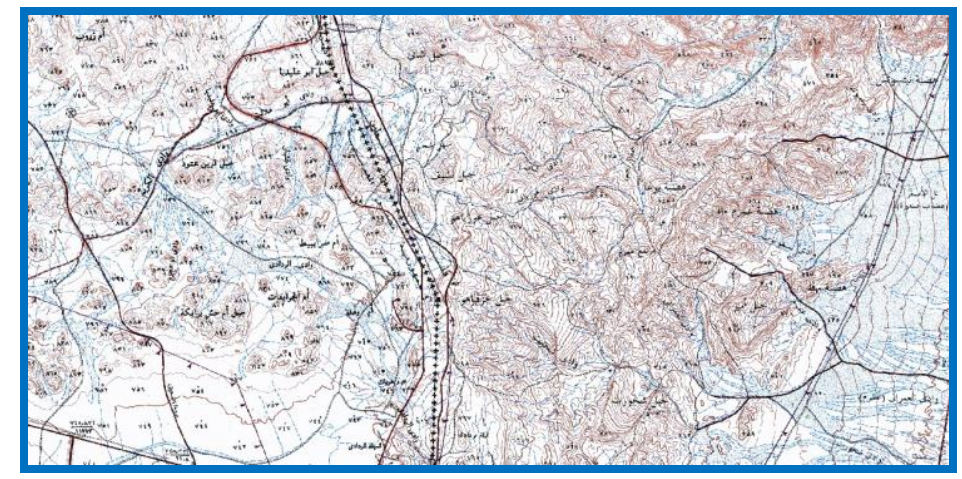

Fig. 1 Topographical map of study area selected

\section{Data Acquisition and Primary Site Selection}

Continuous raster layers are quantitative and have related continuous values. Continuous raster layers can be multiband (e.g., Landsat TM) or single band (e.g., SPOT panchromatic).

Satellite images, aerial photographs, elevation data, scanned maps, and other continuous raster layers can be incorporated into a database and provide a wealth of information that is not available in thematic layers or vector layers. In fact, these layers often form the foundation of the database. Extremely accurate base maps can be created from rectified satellite images or ortho aerial photographs (orthophoto). Then, all other layers that are added to the database can be registered to this base map. Thematic data are typically represented as single layers of information stored as image files and containing discrete classes. Classes are simply categories of pixels which represent the same condition. An example of a thematic layer is a 
vegetation classification with discrete classes representing coniferous forest, deciduous forest, wetlands, agriculture and / or grass.

A thematic layer is sometimes called a variable, because it represents one of many characteristics about the study area. Since thematic layers usually have only one band, they are usually displayed in pseudo color mode, where particular colors are often assigned to help visualize the information.[4].

The rules for layers to be formed are based upon the spatial information about the terrain as desired by a particular military operation. A number of spatial raster data layers are prepared in order to apply the constraints and extract thematic data used to find out the final results. The data for the study area has primarily been collected from the topographical map and/or by on-screen digitizing the scanned map in ERDAS Imagine.

\subsection{Digital Elevation Model (DEM)}

Topographic data are usually expressed as a series of points with $\mathrm{X}, \mathrm{Y}$, and $\mathrm{Z}$ values.

When topographic data are collected in the field, they are surveyed at a series of points including the extreme high and low points of the terrain along features of interest that define the topography such as streams and ridge lines, and at various points in between. On the other hand, elevation data are derived from ground control points and through photogrammetric plotters. It also can be generated through digital orthographic methods. The DEM are continuous raster layers in which data file values represent elevation [5]. DEM made by ASTER sensor with an accuracy of $(29 \mathrm{~m})$ was used to establish DEM for the study area as shown in figure 2 .

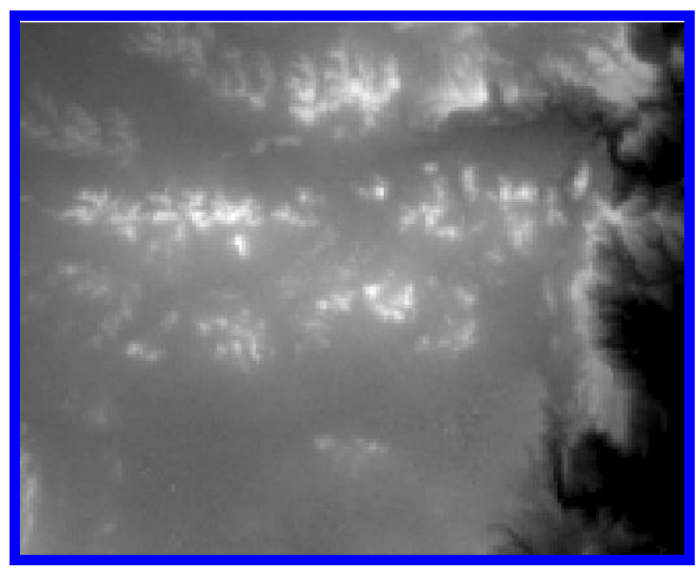

Fig. 2 Raster DEM of study area

\subsection{Drainage Pattern}

Flash Floods are one of the most damaging and costly natural hazards in Egypt, particularly in Sinai Peninsula. Therefore, hydrological modeling and hydrodynamic simulations, to understand and forecast flash flood events, are highly needed. Digital elevation model is the key component in such hydrological and hydrodynamic modeling, which can be used to obtain hydrological parameters about the morphology and drainage network of a watershed [5]. ARC GIS software, spatial analyst tool[9], was used to study drainage pattern for the study area[8] as shown in figure 3 . 


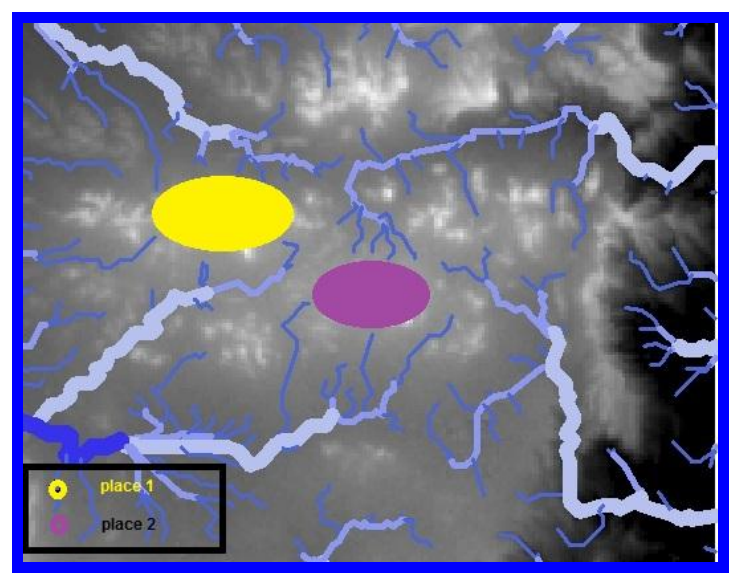

\section{Fig. 3 Drainage pattern for area of interest}

\subsection{Primary Site Selection Using Satellite Image}

In order to choose the suitable places for military camping, the drainage pattern layer will be overlaid on the DEM layer and the resulted suitable places were determined as shown in figure 3. By reviewing the topographic map for the study area place 1 is covered with chain of mountains without any corridors or roads passed closer to it, and then this place will be ignored. Geoprocessing, geometric correction and enhancement, were applied to SPOT multiband of high resolution of 15meter that captured at 2010 for the place 2 as shown in figure 4.

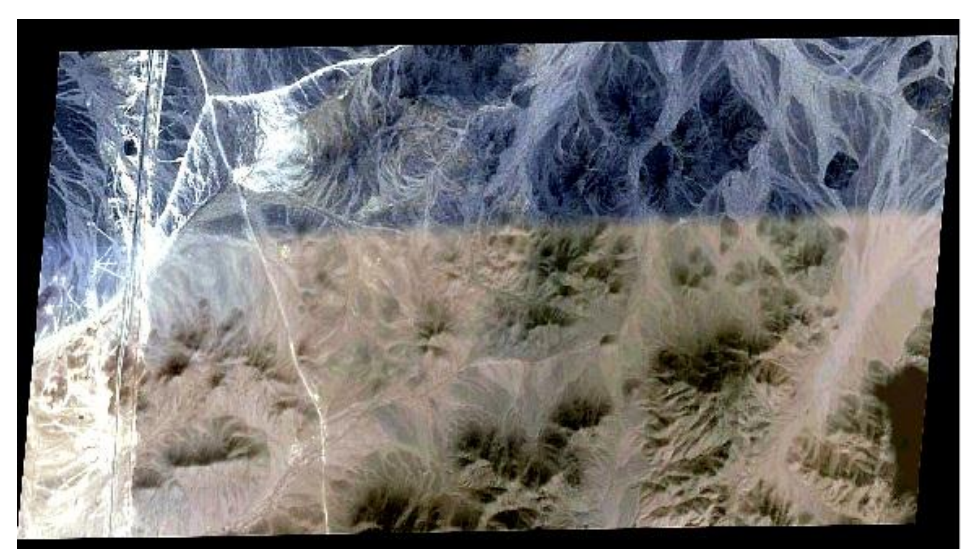

Fig. 4 Satellite image for place 2

\subsection{Slope Layer}

Slope is expressed as the change in elevation over a certain distance. In this case, the certain distance is the size of the pixel. Slope is most often expressed as a percentage, but can also be calculated in degrees. [3]

Using the ERDAS imagine spatial modeler, the slope percent will be calculated all over the DEM of the area of interest (place 2). Raster percent slope for the study area, as shown in figure $5(5 \%)$ [9] meets the mobile criteria and equipment. 


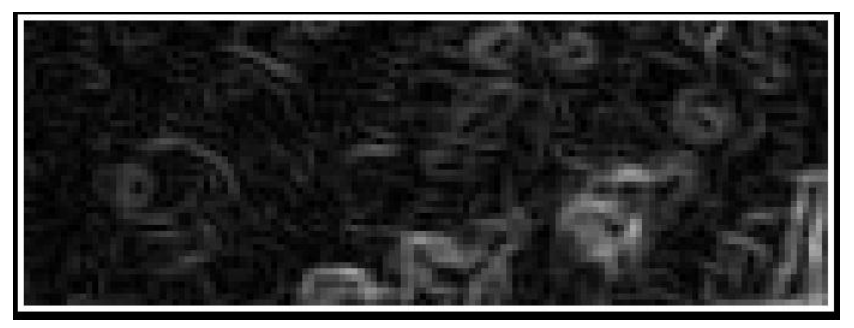

Fig. 5 Raster percent slope of study area

\subsection{Roads Network}

In the broadest sense, digitizing refers to any process that converts non digital data into numbers. However, in ERDAS IMAGINE, the digitizing of vectors refers to the creation of vector data from hardcopy materials or raster images that are traced using a digitizer keypad on a digitizing tablet or a mouse on a displayed image. Any image not already in digital format must be scanned before it can be read by the computer and incorporated into the database. Certain features (roads) can be extracted from a digital image to include in a vector layer. Tablet digitizing and screen digitizing enable users to digitize these features of a map or photograph, such as roads, ways among mountains and valleys [6].

Roads, corridors and routes were determined by digitizing topographic map and the satellite image for the study area as seen in figure 6.

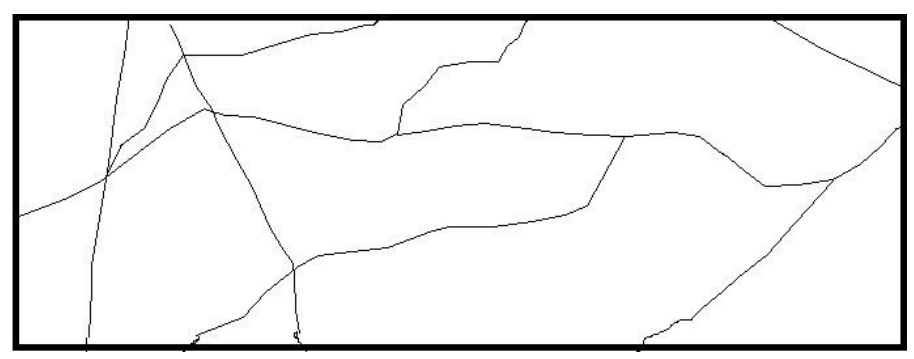

Fig. 6 Vector layer of roads network

\section{Results of Applying Conditions on the Layers}

\subsection{Vehicles Capability}

According to the roads and transport authority and the specifications of most the vehicles may be used its hypothecs that the slope shouldn't exceed 5\% [10]. Thus by applying this condition on the slope layer to obtain the areas with the slope lower than 5\% the spatial model maker of ERDAS imagine will be used to produce the desired result as shown on figure 7.

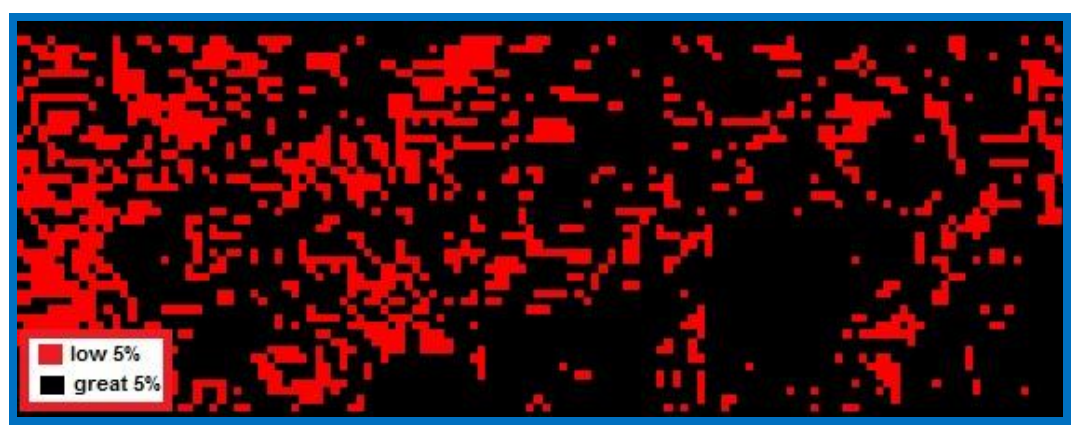

Fig. 7 Slope under 5\% 


\subsection{Roads Intervisibility}

In order to select a place for special purpose, a small military camp, that is not visible for all the passengers who use roads and corridors close to it, ERDAS IMAGINE route intervisibility applications were applied to figure out those places taken into consideration ad distance of 1000 meters as shown on figure 8 .

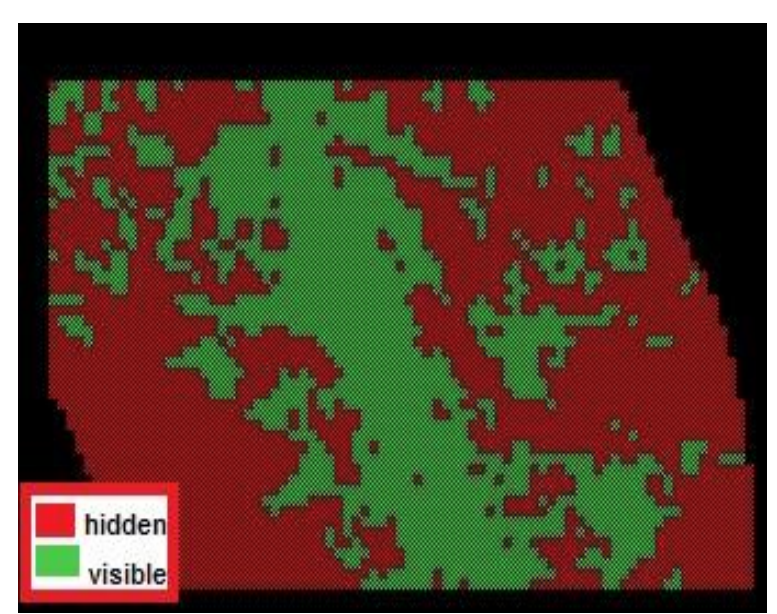

Roads (1-3-5)

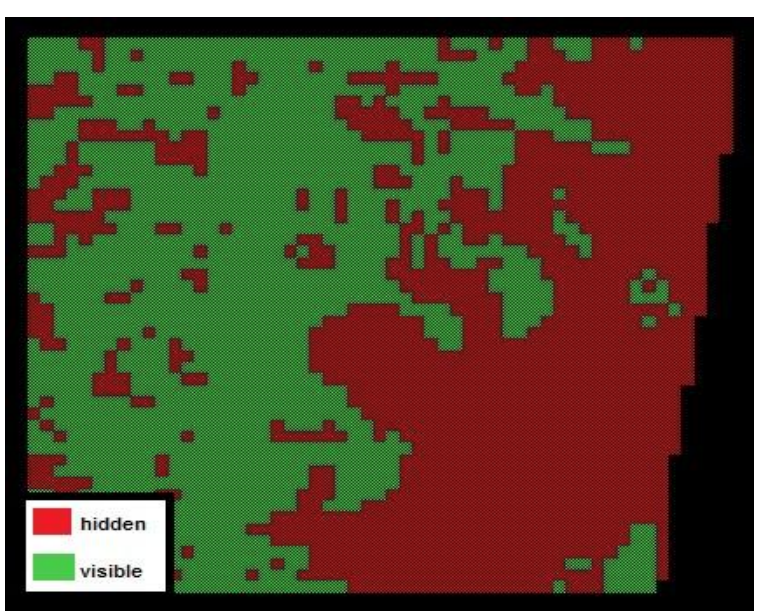

Roads (4-6-7)

Fig. 8 Invisible places from surrounding roads

\section{Decision Maker Preparation}

\subsection{The Need for Spatial Modeler Decision Maker}

Most of data acquired in the previous title, 4. , requires good interpretation skills to present the relief of ground surface. This may adversely affect the site selection, therefore there is a need to standardize procedures and incorporate systems, which use the existing knowledge acquired by experts, intelligence and other means. Decision Maker Support (DMS) tool can be effectively used to make accurate decision for site selection which can easily be used by military commanders at all levels.

DMS can be developed by taking into consideration the experience and knowledge of terrain analysts and other experts to convert them into a set of rules. These rules can then be applied to digital data to derive a number of thematic maps that can in turn be used in site selection. The decision maker support organizes the information into rules, which are generally written in the form of IF-THEN-ELSE statements. The user interface is the link between the user and the decision maker such that a non-expert can also use it comfortably. With passage of time, the decision maker support has to be updated in terms of information's and rules, thus mechanism to update DMS is an essential facility to upgrade and check the validity of DMS. In this paper, ARC map spatial analyst tools, ERDAS Imagine spatial modeler and ERDAS Macro Language were used to create the DMS.[3]

\subsection{Modeling}

Modeling is a powerful and flexible analysis tool. It is the process of creating new layers from combining or operating upon existing layers. Modeling enables us to create a small set of layers perhaps even a single layer which contains many types of information about the study area. Models can be created graphically and resemble a flow chart of steps, or they can be created using a script language. Input files are defined, functions and/or operators are specified, and outputs are defined. The model is run and a new output layer(s) is created. 
Models can utilize analysis functions that have been previously defined, or new functions can be created.[6]

The Spatial Modeler consists of a digital flow charting structure built graphically on the screen. With simple points and clicks, complex models are rapidly built to generate all types of products. Included in the Spatial Modeler are hundreds of functions to perform calculations to buffering distance around features, or the intersection/overlap of two features; provide decision rules with multiple variables, and analyze elevation values for slope and aspect. Models can be built and saved in a model library. With the ERDAS Macro Language (EML), a graphical user interface can be added to any model, and the end user can easily add the appropriate files names and initiate the modeling process with the touch of a button [7].

\subsection{ERDAS MACRO LANGUAGE (EML) Code}

EML is designed to serve as a scripting language as well as a user interface language. Unlike simple user interface description tools EML is able to define the actions which are taken when a user interacts with a dialog. It provides a complete syntax for defining a typical dialog box, as well as constructs for defining scripts which contain branching and control logic. In addition to the macro language itself, EML provides a $\mathrm{C}$ level toolkit of functions which allows the programmer to build the EML language into an application, and to extend the language through application specific variables, functions and commands. The code for creating the interface was written as shown in figure 9.

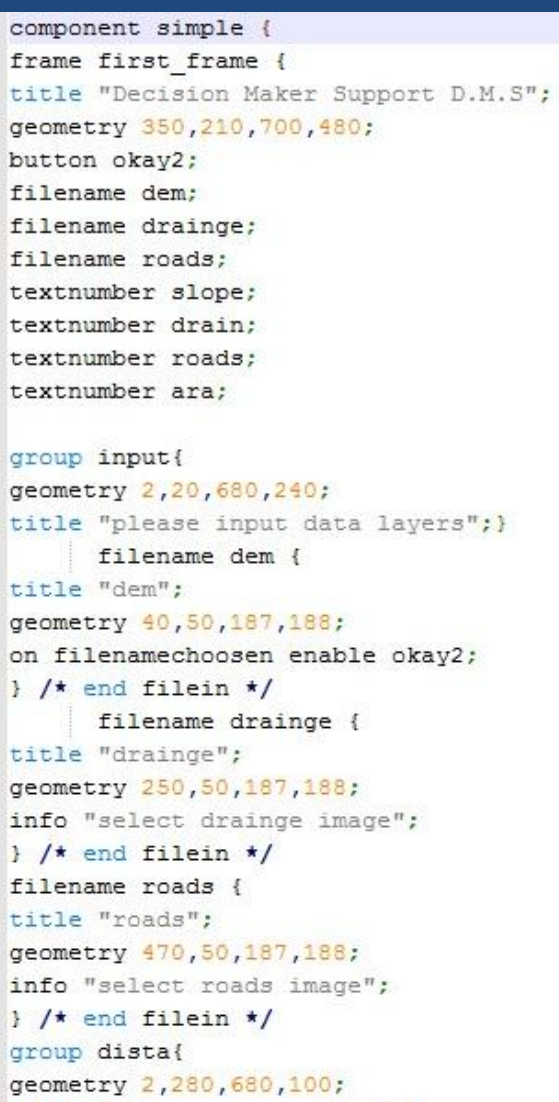

Fig. 9 EML Code 


\subsection{Results of Modeling}

\subsubsection{Roads intervisibility combination}

The hidden places could be used to select the best site for each road individually with the aid of the model maker of ERDAS IMAGINE see figure 10. The places that are hidden from the entire roads network were resulted as shown in figure 11.[6]
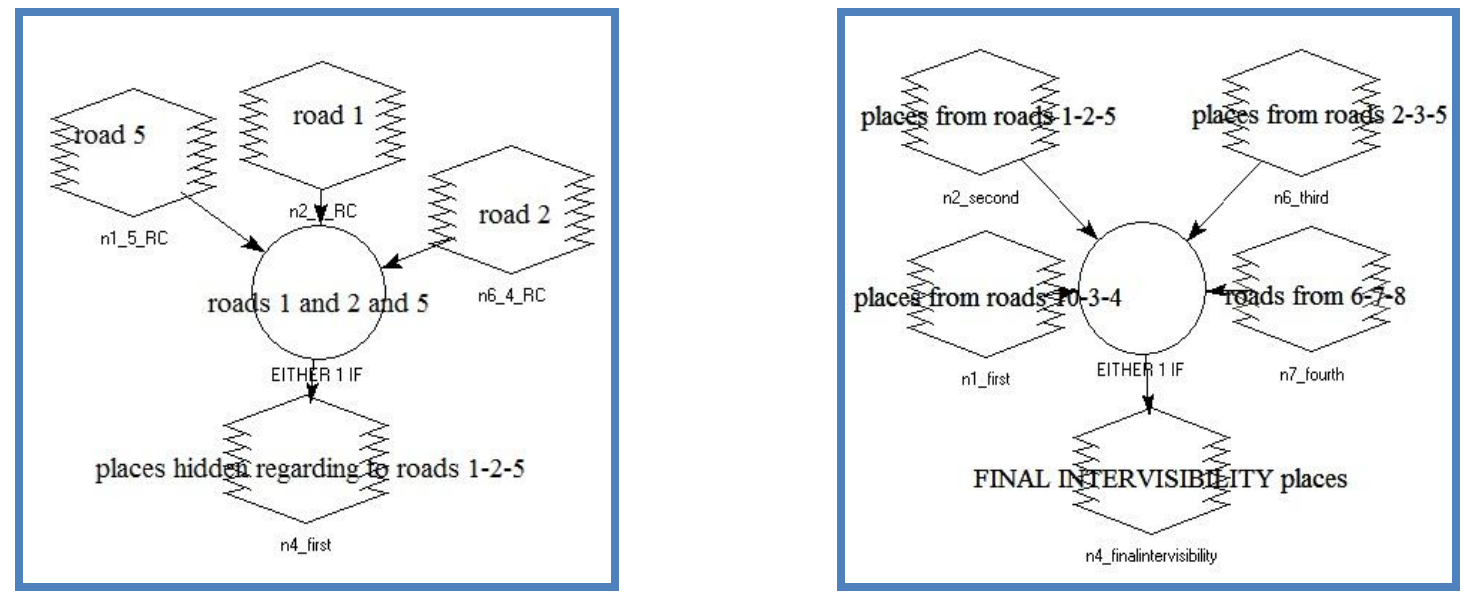

Fig 10 Model maker programming.

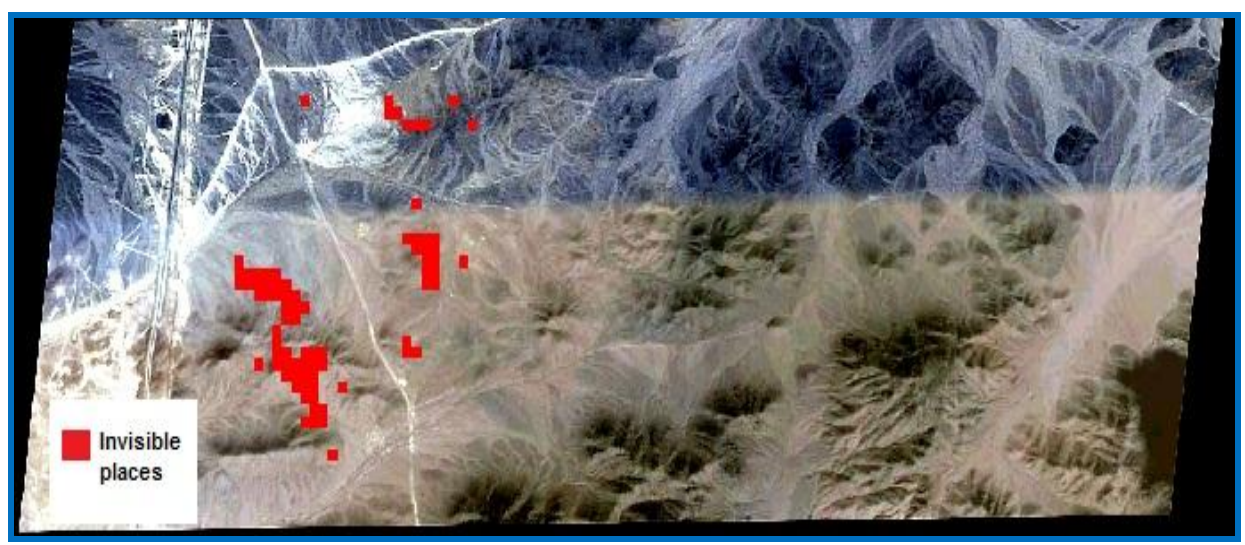

Fig 11 Final intervisibility places

\subsubsection{Slope, roads intervisibility and drainage pattern combination.}

Now after realizing the suitable places according to each condition separately we will use the model maker application to create a model that combine the results from all the conditions, see figure 12, and get the proposed suitable places as shown in figure 13 . 


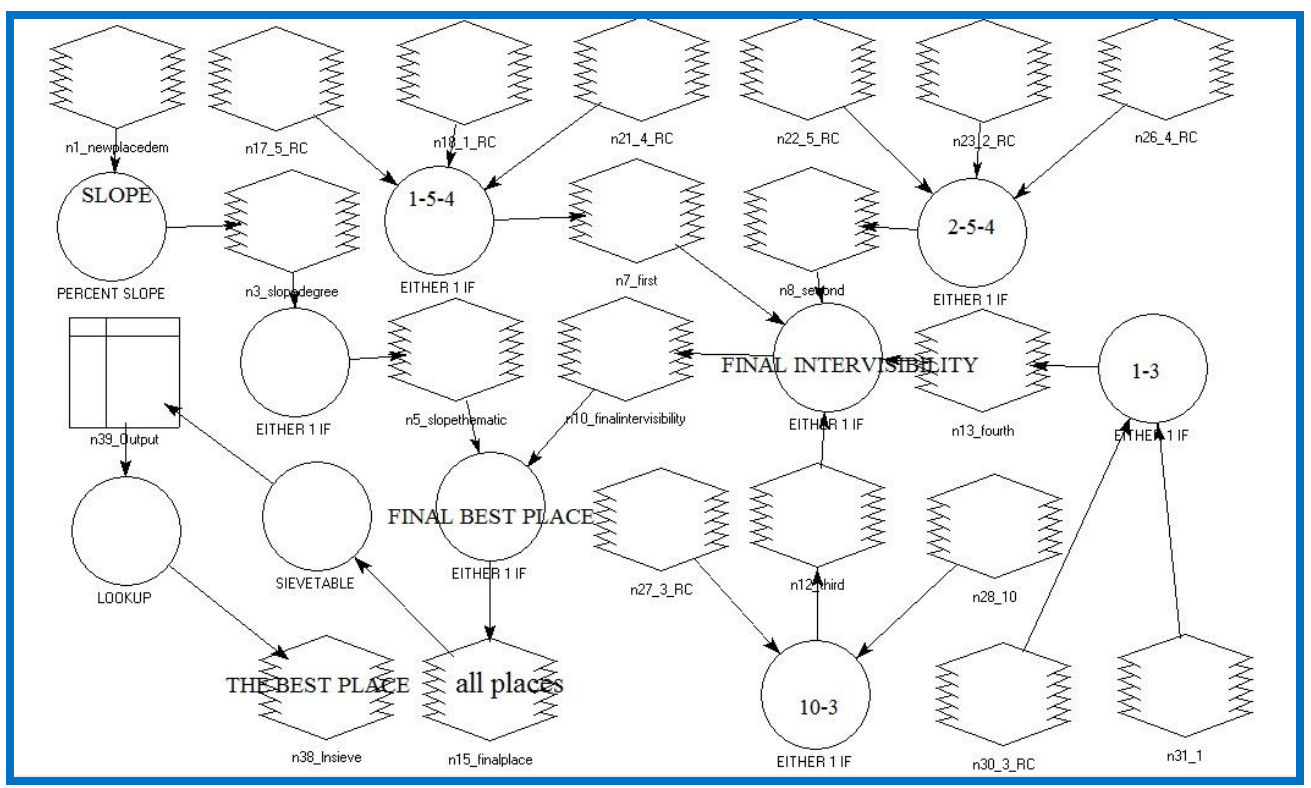

Fig.12 Final model.

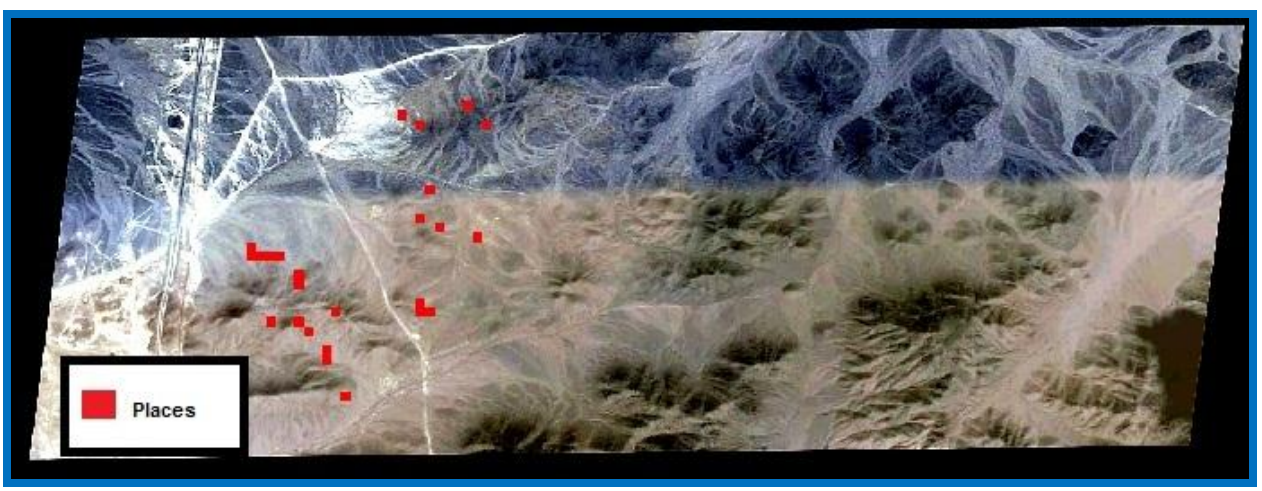

Fig.13 Proposed places

\subsection{Decision of the Best Areas}

The proposed places are the places that are suitable according to the conditions mentioned before but still there is a very important condition should be took into consideration and this is the area of the site needed to be used for occupation. From the data acquisition it is known that the area for each pixel is 29X29 meters, and then we will apply a function of sieve the raster to ignore the proposed places that is not met the required area (less than 3 pixels). The best areas are shown in figure 14 . 


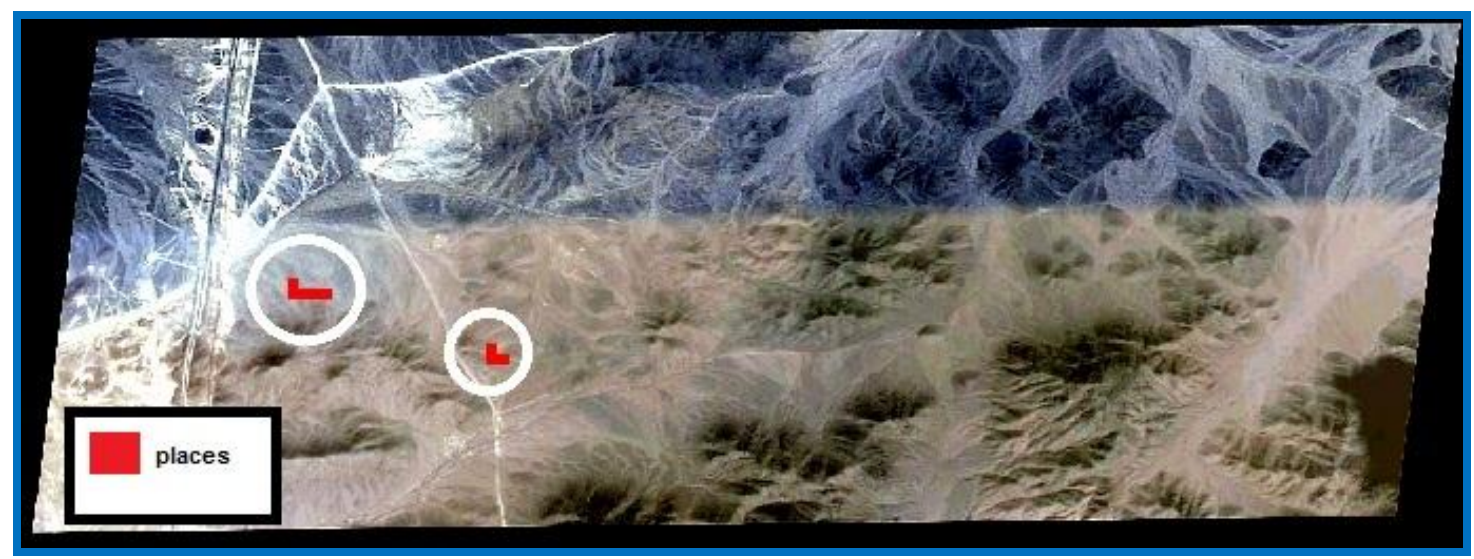

Fig 14 Best sieved areas

\subsection{D.M.S Interface}

The above final results obtained for only one location and for specific mission, we use the EML as a programming language to create an application to do the above process altogether so that a commander on the field can do all the above process easily. He will be asked only to input the main data such as digital elevation model, drainage pattern, and the roads network. Then decide the specific conditions he needs such as the safe slope for his vehicles, the distance from roads network that couldn't be discoverable, and the area for the sites he need for his forces. The (D.M.S) interface working under the ERDAS IMAGINE software is bonded with the models created before by the model maker. The model allows any correct data to be entered on the model according to the (D.M.S) input data interface as shown on figure 15 .

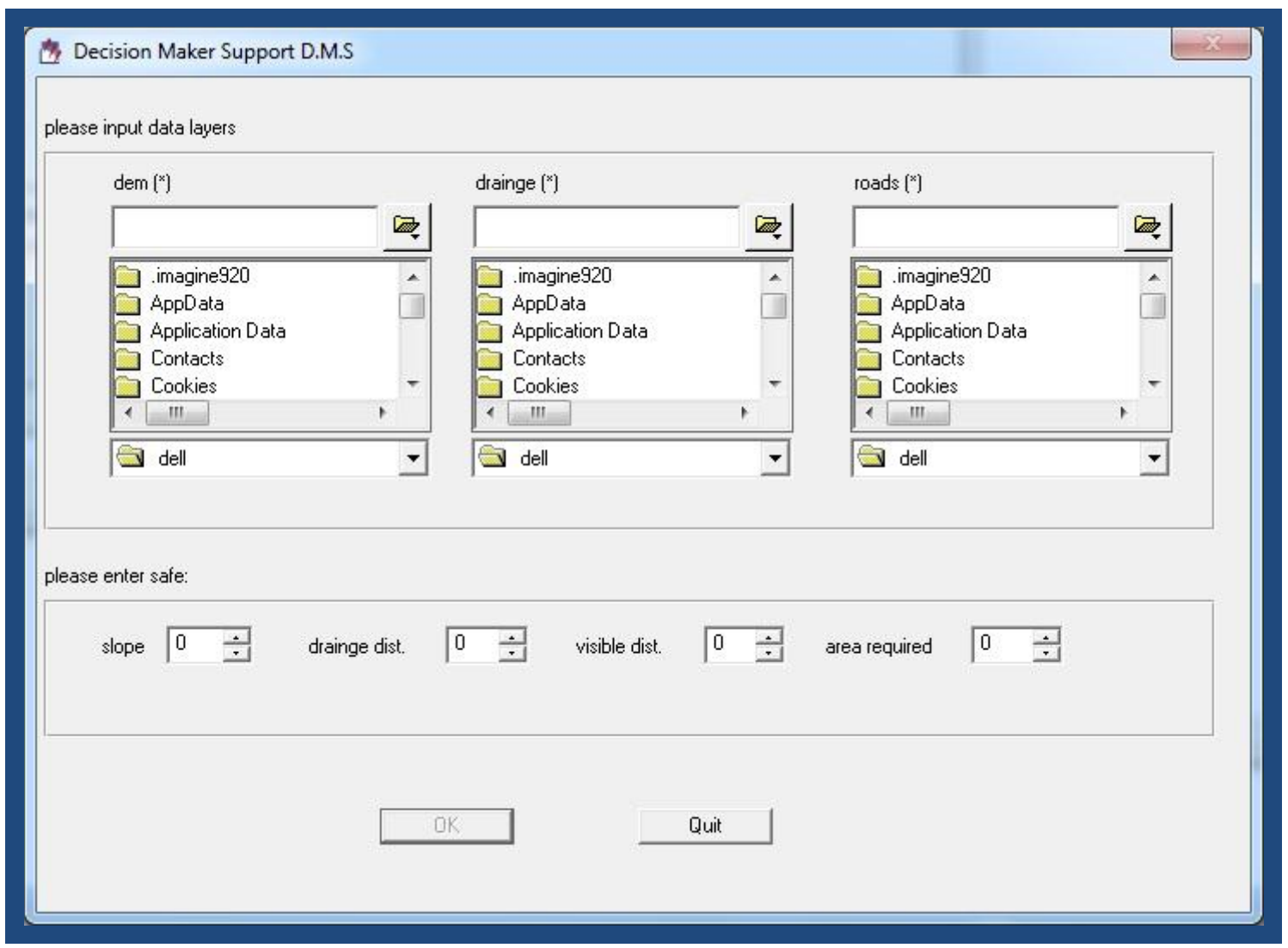

Fig.15. D.M.S interface 


\section{Conclusions}

- The Spatial Modeler consists of a digital flow charting structure built graphically on the screen by an analyst.

- With simple points and clicks, complex models are rapidly built to generate all types of products.

- Included in the Spatial Modeler are hundreds of functions to perform calculations to buffering distance around features, or the intersection, overlap of two features

- EML is designed to serve as a scripting language as well as a user interface language.

- Unlike simple user interface description tools EML is able to define the actions which are to be taken when a user interacts with a dialog.

- EML provides a complete syntax for defining a typical dialog box, as well as constructs for defining scripts which contain branching and control logic.

- In addition to the macro language itself, EML provides a $C$ level toolkit of functions which allows the programmer to build the EML language into an application, and to extend the language through application specific variables, functions, and commands.

\section{References}

[1] Edward P. Chamberlayne (2002). A GIS Model for Minefield Area Prediction, Blacksburg, VA, USA.

[2] Steven Douglas Fleming (2004). Geospatial Information for Joint Military Operations in the Littoral Zone. The University of Georgia May 2004,.

[3] ERDAS Field Guide ${ }^{\mathrm{TM}}$ (fifth edition), ERDAS, Inc. Atlanta, Georgia

[4] Bgis introduction to GIS, David J.BUckey

[5] Garbrecht, J., and Martz, L. W. (1999), TOPAZ: An Automated Digital Landscape Analysis Tool for Topographic Evaluation, Drainage Identification, Watershed Segmentation and Subcatchment Parameterization.

[6] Schowengerdt, Robert A. (2007). Remote sensing: models and methods for image processing (3rd ed.). Academic Press. p. 2. ISBN 978-0-12-369407-2. http://books.google.com/books?id=KQXNaDH0X-IC\&pg=PA2.

[7] ERDAS IMAGINET tour Guides TMERDAS IMAGINE ${ }^{\circledR}$ V8.5 ERDAS ${ }^{\circledR}$, Inc. Atlanta, Georgia

[8] Graham, Steve (2002). "Introduction to ArcToolbox" (PDF). Penn State. http://www.pop.psu.edu/gia-core/pdfs/gis_rd_02-15.pdf. Retrieved 2008-02-11

[9] Engineering guide for roads design(June 2009). 